\title{
On the case
}

\section{White coats and fingerprints: diagnostic reasoning in medicine and investigative methods of fictional detectives}

\author{
Claudio Rapezzi, Roberto Ferrari, Angelo Branzi
}

Current trends toward routine mass use of sophisticated diagnostic tools is killing off the science and art of clinical reasoning. An ideal clinician would present a harmonic fusion of almost all the investigative methods of fictional detectives and avoid slavish adherence to protocols and procedures

Our underlying premise is that the current trend towards mass use of sophisticated diagnostic tools in routine practice-accompanied by a blind faith in technology and predefined diagnostic algorithms-is threatening to kill off the science and art of clinical reasoning. Besides burning a lot of public and private money to make diagnostic work rather superficial, doctors also risk losing the intellectual pleasure that comes from careful diagnostic reasoning.

Clinical analogies with detective fiction generally revolve around Sherlock Holmes. ${ }^{12}$ However, like medicine, detective fiction has subspecialties and intellectual trends. ${ }^{3}$ A rapid overview of the analogies between diagnostic reasoning and the investigative strategies found in detective literature may provide us with some clues on how to confront the problems posed by the burgeoning number of available technologies.

\section{Clinician-detective analogies}

"Detective work" has long been a metaphor for clinical acumen. Clinical reasoning and the detective fiction genre show many similarities in their cultural background and context (box 1). Both try to restore a status quo that has been undermined by a crime or disease. During their golden age, the two disciplines thrived on a climate of faith in the apparently unlimited capabilities of science and based their methods on deterministic interpretation of clues, signs, and symptoms. Detectives and clinicians reach a final, reasoned "diagnosis" by decoding signs (clues) that are often meaningless or disconcerting to the layman. The stupor and admiration that Sherlock Holmes excites when he "guesses" through apparently insignificant details that Watson has been to send a telegram from the Wigmore Street post office 4 is similar to the reaction Dr Trousseau gets when he diagnoses meningitis by producing red streaks on lightly scratching a patient's skin. ${ }^{5}$

It is no coincidence that Sir Arthur Conan Doyle was himself a doctor and that he modelled Sherlock Holmes on his brilliant teacher Joseph Bell, professor of surgery at Edinburgh Medical School. Conan Doyle
Box 1: Some analogies between detective fiction and clinical method

- Born in the same historical period (second half of the 19th century)

- Developed within the same social class (the upper middle classes)

- Shared faith in logic

- Similar working patterns

- Exchange of roles (in crime fiction)

wrote many medical incidents into his stories, ranging from tropical diseases to cardiovascular medicine. ${ }^{6}$ Nevertheless, detective and physician remained two separate figures (Holmes and Watson). Later authors would unite the two roles into a single character, providing us with a series of pathologist-detectives (from R Austin Freeman's Dr Thorndyke to Patricia Cornwell's Dr Kay Scarpetta or the crime fighting television coroner, Quincy).

\section{Investigative models}

In The Sign of Four, Sherlock Holmes states that three qualities are necessary for the ideal detective: "observation, deduction and knowledge." This could be considered the paradigm (and the ideological manifesto) of the detective literature typified by British novelists in the late 19th and early 20th centuries. The golden age of the thriller starred such famous sleuths as Auguste Dupin, Sherlock Holmes, Miss Marple, and Hercule Poirot. Twentieth century detective literature added two other important qualities: the capacity for psychological and environmental modelling of the victimepitomised by Simenon's Maigret and Chesterton's Father Brown-and the ability to spot inconsistencies in crime scenes-typical of Lieutenant Columbo (by Levinson and Link). Here again, clear analogies can be drawn between the ideal profiles of doctors and detectives (box 2).

\section{Figs A-D on bmj.com show illustrative vignettes}

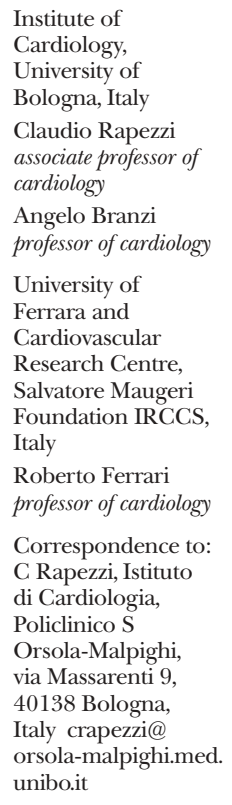

BMJ 2005;331:1491-4

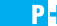


Box 2: Shared characteristics of ideal detectives and clinicians

- Ability in observation

- Ability in "deduction"

- Knowledge

- Ability to reconstruct psychological and social profiles

- Ability to spot inconsistencies

The history of detective literature conventionally dates back to 1841, the year of The Murders in the Rue Morgue by Edgar Allan Poe. ${ }^{7}$ The ensuing century and a half has given us countless tales of investigative ploys entrusted to thousands of more or less famous sleuths. Nevertheless, all the various methods can be broadly classified in the context of just four or five (not necessarily mutually exclusive) underlying models of investigative thought, epitomised by some of the most famous names of detective writing (table).

\begin{abstract}
Ability in observation and logical reasoning
Sherlock Holmes is the prototype-and sometimes the caricature-of this model. Although he describes his method as "deductive," Holmes did not generally apply either deduction (from the general to the particular) or induction (from particular to general) but rather abduction. In the words of the philosopher C S Peirce, "Abduction is the process of forming an explanatory hypothesis" or, put simply, "nothing but guessing." Induction establishes a rule, and deduction merely develops the necessary consequences of a given hypothesis. Only the third of Peirce's classic bean syllogisms (box 3)-the abductive one-leads to a new hypothesis (that those beans have fallen out of the bag) that needs to be tested. Good detectives and good clinicians share the same underlying approach as scientific researchers (Karl Popper's hypotheticodeductive model). ${ }^{9}$
\end{abstract}

Investigative models in detective stories from the 18th century to the present day

\begin{tabular}{lll} 
Dominant feature & Characters & Author \\
\hline $\begin{array}{lll}\text { Observational capacity,capacity for logical reasoning } \\
\text { (deduction, induction, abduction) }\end{array}$ & Zadig & Voltaire \\
\cline { 2 - 3 } & Auguste Dupin & Edgar Allan Poe \\
\cline { 2 - 3 } & Sherlock Holmes & Conan Doyle \\
\cline { 2 - 3 } & Hercules Poirot & Agatha Christie \\
\cline { 2 - 3 } & Miss Marple & Agatha Christie \\
\cline { 2 - 3 } & Philo Vance & S S Van Dyne \\
\cline { 2 - 3 } & Ellery Queen & F Danny and M B Lee \\
\cline { 2 - 3 } & William of Baskerville & Umberto Eco \\
\hline Knowledge & Nero Wolfe & Rex Stout \\
\cline { 2 - 3 } & Miss Marple & Agatha Christie \\
\hline Ability to reconstruct psychological and social profiles & Maigret & Simenon \\
\cline { 2 - 3 } and to conduct an interview & Father Brown & G K Chesterton \\
\cline { 2 - 3 } & Charlie Chan & E D Biggers \\
\hline Ability to recognise inconsistencies and to spot fine & Columbo & Levinson and Link \\
distinctions & & Raymond Chandler \\
\hline Action, obstinacy, tenacity, initiative & Philip Marlowe & R MacDonald \\
\cline { 2 - 3 } & Lew Archer & D Hammett \\
\cline { 2 - 3 } & Sam Spade & Mickey Spillane \\
\cline { 2 - 3 } & Mike Hammer & Conan Doyle \\
\hline Slavish adherence to protocols and procedures & Lestrade & (and many others) \\
& (and countless & inexperienced and/or \\
& stolid police officers) & \\
\hline
\end{tabular}

Holmes's observations focus not only on the presence of facts and evidence but also on their absence. A classic example is when Inspector Gregory interviews Holmes, who is trying to find a missing race horse (Silver Blaze) and to identify the killer of its trainer:

"Is there any point to which you would wish to draw my attention?"

"To the curious incident of the $\operatorname{dog}$ in the night-time."

"The dog did nothing in the night-time."

"That was the curious incident," remarked Sherlock Holmes. ${ }^{10}$

Actually, the dog had failed to bark because it was the trainer himself who had led Silver Blaze from the stable to lame it. The horse had lashed out in fright, killing the trainer-who takes on the dual role of victim and culprit

Many of Sherlock Holmes's best aphorisms provide a perfect fit with the medical world and hospital life (box $4),{ }^{41-15}$ and could be uttered by any physician affected by an inflated ego similar to that displayed by Holmes.

In the long history of medicine, the discovery and interpretation of signs of disease are relatively recent features of diagnosis. The glamour and popularity of the "pathognomonic signs" described by the famous anatomical clinicians of the 18th and 19th centuries (Laennec, Auenbrugger, Trousseau, Austin-Flint, Cheyne-Stokes) emanated from the flawed belief that the "internal site" of a disease can be diagnosed with absolute precision from its "specific external signs." Even today, the search for pathognomonic signs often forms the first approach in the undergraduate formation of future doctors. Only later does the medic overcome blind faith in the "science" of clinical and instrumental signs, recognising their limitations (see fig A on bmj.com).

\section{Knowledge}

General knowledge and a specific mental archive of past cases are known requisites for the success of an investigation. However, for armchair detectives such as Nero Wolfe, such learning becomes the main-if not the only-tool for solving cases. Shying away from all direct contact with the real world, Wolfe keeps to the New York apartment where he tends his orchids. However, his knowledge of crime and his general learning are so vast that they allow him to solve almost any case-just as long as his assistant, Archie Goodwin, remains in contact with the outside world. ${ }^{16}$ The accumulation of knowledge is a delicate process that risks consuming a person's entire intellectual energy. Sherlock Holmes has clear ideas on this: "I consider that a man's brain originally is like a little empty attic, and you have to stock it with such furniture as you choose. He will have nothing but the tools which may help him in doing his work. It is a mistake to think that that little room has elastic walls and can distend to any extent. Depend upon it there comes a time when for every addition of knowledge you forget something that you knew before. It is of the highest importance, therefore, not to have useless facts elbowing out the useful ones." ${ }^{14}$ Nowadays, the internet is the tool of choice to access and store huge amounts of knowledge without clogging up the brain. The emergence of a new prototype doctor is a growing risk: an "armchair" specialist armed with a high speed laptop and the conviction 


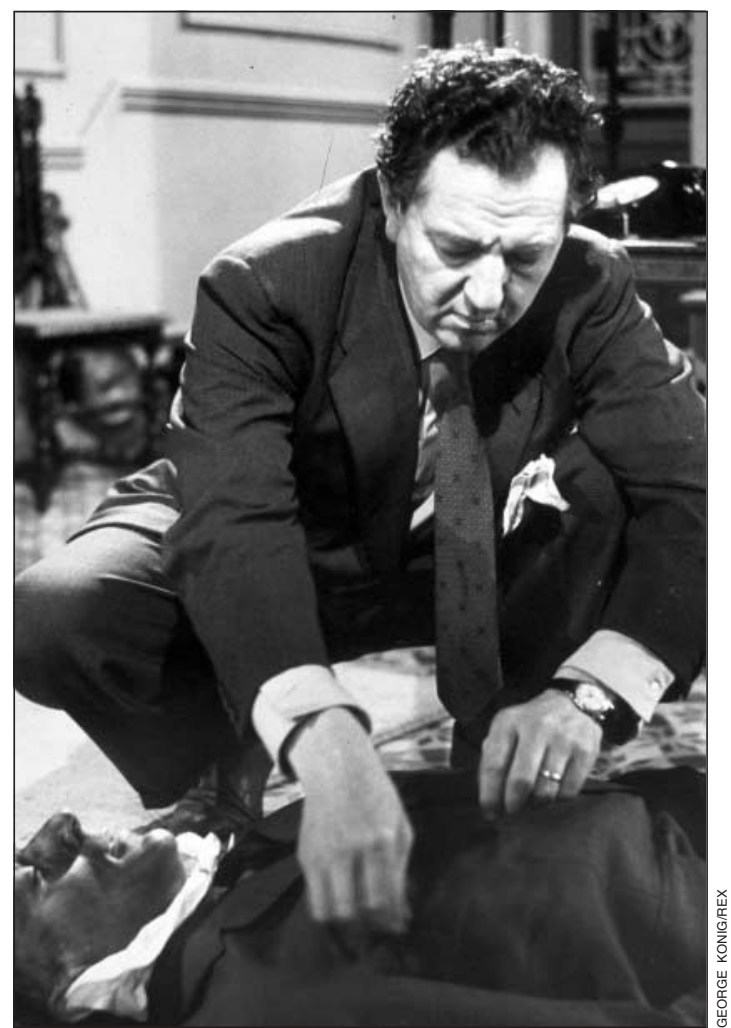

Maigret reconstructs a profile

that the solution to every clinical dilemma is to be found on the web. Well conducted PubMed searches for similar cases are worthwhile if, and only if, the clinician conserves his bedside role-the Archie Goodwin side of his professional identity (see fig $\mathrm{B}$ on bmj.com). Otherwise, the budding expert has little or no chance of achieving the enviable success rates of Nero Wolfe.

\section{Reconstruct psychological and social profiles}

The prototype here is Maigret. Simenon's famous inspector apparently follows no scientific method of investigation. He literally enters the world of the victim, reaching a sort of physical and psychic identification. In The Dead Mr Gallet, when he is asked, "Are you investigating the murderer or the victim?" Maigret quietly replies, "I will identify the murderer when I fully know the victim."17 Maigret gives almost manic attention to interviewing the possible perpetrator. Long, overnight interviews usually end at dawn with the murderer's confession and a hearty breakfast in Dauphine's alehouse.

The interview is a vital investigative tool for the vast majority of detectives; in some cases, the interview can be the sole means of detection. In Murder on the Orient Express Poirot solves the case largely with information he systematically obtains from the suspects. ${ }^{18}$

Throughout the 18th century, doctors based their diagnoses mainly on their patients' spontaneous verbal communications. As diseases were categorised by symptoms, patients could communicate their symptoms verbally, or even by letter. Thus, doctors could effectively "visit" a patient (make a diagnosis) by post. During the 19th century, the patient's history progressively began to be articulated into a standard protocol in the form of an interview, with less time being dedicated to free verbal communication and the patient's own interpretations.

This structured approach has helped generations of investigators and clinicians to become valid professionals. For Maigret or Father Brown, however, the interview remains an extemporary process guided by intuition rather than a standard procedure. All of us have met colleagues who have a special talent for interviewing their patients and extracting the fundamental elements needed for a correct diagnosis. This art is probably an individual talent that can only partially be transmitted to students and coworkers, although beginners should remember that diagnostic information is gained not through a freewheeling dialogue with the patient but through active probing of precise diagnostic hypotheses.

\section{Ability to recognise inconsistencies}

Lieutenant Columbo, the homicide investigator created by Levinson and Link-and popularised by Peter Falk's interpretation-has a peculiar ability to pick out inconsistencies in crime situations. For example, if the victim is a rich guy with a refined lifestyle, why was he drinking cheap champagne in his bedroom? Most likely the scene was a set up, and the original impression was misleading. ${ }^{19}$

Similarly, I may be wondering how normal, or even low, voltage electrocardiogram can possibly be consistent with the diagnosis of hypertrophic cardiomyopathy clearly suggested by the echocardiogram in fig $\mathrm{C}$ on bmj.com. Identification of this inconsistency forces me to reconsider my assumptions and to evaluate new hypotheses-possibly leading me to a diagnosis of cardiac amyloidosis. It looks easy on television, but the capacity to perceive and assign correct values to internal discrepancies requires a command of the entire diagnostic scenario. This talent needs a blend of observational capacity, logical reasoning, culture, and abductive imagination-a highly advanced and integrated phase in the process of clinical evaluation.

\section{Action, obstinacy, and initiative}

From the 1930 s and ' 40 s, a new subgenre started to appeal to readers: "noir" in French, "hard boiled" in American slang. Here, logical reasoning gives way to action, tenacity, initiative, obstinacy, disenchantment, and disillusionment, with indiscriminate use of all available techniques (chases, interceptions, forced confessions). ${ }^{20}$ The shadowy figures of Philip Marlowe and

\section{Box 3: Deduction, induction, abduction}

\section{Deduction}

Rule: all the beans from this bag are white Case: these beans were contained in this bag Result: these beans are white

\section{Induction}

Rule: these beans from this bag are white Case: these beans are white Result: all the beans from this bag are white

\section{Abduction}

Rule: all the beans from this bag are white Case: these beans are white Result: these beans were contained in this bag 
Sam Spade-both unforgettably portrayed by Humphrey Bogart-epitomised this new current.

For a correspondence within the medical field, we can transpose the dim, smoke filled office of our hard boiled private eye-overlooking the wet asphalt of a crime ridden metropolis-into the dimly lit basement of certain chaotic inner city hospitals. Inside, a bored, angry, and unmotivated clinician is ordering up endless tests and procedures-without any precise hypothesis-in the vague hope of stumbling on a plausible diagnosis.

\section{Slavish adherence to protocols and procedures}

In a widely used literary device, the investigative genius of the protagonist shines out against a background of slavish adhesion to the institutional procedures by an official counterpart (for example, Lestrade $v$ Holmes). Why do these archetypes of officialdom behave so stolidly and ineffectively? Fear of making mistakes, attracting rebukes from superiors, and incurring official sanctions plays a part, often alongside inexperience and a dull or lazy mindset.

Can a parallel be drawn with a literal and uncritical implementation of clinical guidelines? Within a medical community, the existence of guidelines raises the average level of quality of practice and lowers the risk of accidents. However, uncritical application of recommendations can lead to pitfalls (see fig D on bmj.com). A juridical approach to guidelines can also lead the clinician to systematically abandon pathophysiological and clinical reasoning in favour of a purely defensive form of medicine owing to the fear of leaving space for the creativity of lawyers. Last but not least is the risk that a set of statements drawn up and provisionally shared by a panel of experts (guidelines) can assume the status of a Papal edict (official dogma), thereby retarding or impeding the potential for innovation.

\section{Clinical method as the science and art of investigation}

An ideal clinician could be said to present a harmonic fusion of almost all the investigative models outlined above - a rare event. If one investigative quality marks out the mature clinician it is the ability to spot possible inconsistencies among the clinical, instrumental, and laboratory examinations, considering not only what is present but also what is missing. This requires skills in observation and "deduction," handling of knowledge, pattern recognition, and the astuteness that comes

\section{Box 4: Sherlock Holmes aphorisms}

- You see, but you do not observe ${ }^{11}$

- You know my method. It is founded upon the observation of trifles ${ }^{12}$

- Never trust to general impressions, my boy, but concentrate yourself upon details ${ }^{13}$

- It is a capital mistake to theorise before one has data. Insensibly one begins to twist facts to suit theories, instead of theories to suit facts ${ }^{1}$

- There is nothing like first-hand evidence ${ }^{14}$

- There is nothing more deceptive than an obvious fact ${ }^{12}$

- The world is full of obvious things which nobody by any chance ever observes $^{15}$

-When you have eliminated all which is impossible, then whatever remains, however improbable, must be the truth

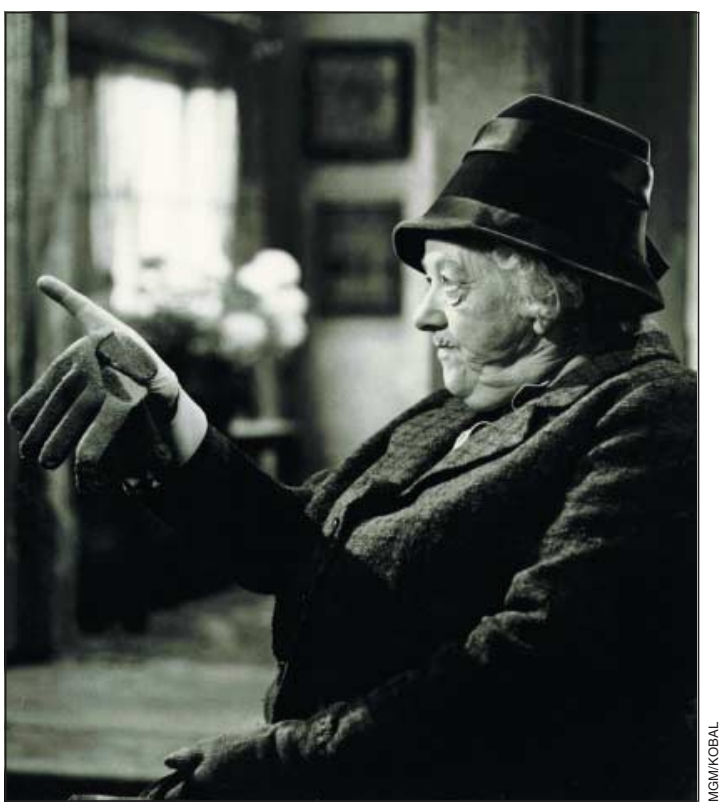

Miss Marple: deduction, induction, abduction

from years of experience. For well honed clinicians, the clinical part of the diagnostic investigation is not just a question of medical history and physical examination but rather the capacity to establish links among various physical and laboratory or instrumental findings with an eye to both the consistencies and inconsistencies. In this context, simple examinations really do have the same value as the more complex and expensive ones.

We thank Robin M T Cooke for reviewing the manuscript.

Contributors: CR conceived, drafted, and revised the work. RF and $\mathrm{AB}$ contributed with suggestions and revisions in all phases of the writing. CR is the guarantor.

Funding: None.

Competing interests: None declared.

1 Peschel RE, Peschel E. What physicians have in common with Sherlock Holmes: discussion paper. JR Soc Med 1989;82:33-6.

Eco U, Sebeok TA, eds. The sign of three:Dupin, Holmes, Peirce. Bloomington, Indiana: University Press, 1983.

Rapezzi C. Crimini e malattie: metodo clinico e metodo investigativo poliziesco a confronto. It Heart J Suppl 2003:4:415-9.

4 Conan Doyle A. The sign of four. London: Lippincott's Magazine, February 1890.

1890.

Trousseau A. Lectures on clinical medicine, delivered at the Hotel-Dieu, Paris. Translated and edited with notes and appendices by P Victor Bazire London: The New Sydenham Society, 1872.

6 Ramanan SV. Cardiovascular disease in the adventures of Sherlock Holmes. Arch Intern Med 2001;161:701-5.

Allan Poe E. The murders in the rue Morgue. New York: Graham's Lady's and Gentleman's Magazine, April 1841.

Hartshorne C, Weiss P, Burks AW, eds. Collected papers of Charles Sanders Peirce. Cambridge, MA: Harvard University Press, 1966

9 Popper K. The logic of scientific discovery. London: Hutchinson, 1959.

10 Conan Doyle A Silver Blaze. London: Strand Magazine, Decer 1892

10 Conan Doyle A. Situer Blaze. London. Strand Magazine, December 1892

1 Conan Doyle A. A scandat in Bohemia. London: Strand Magazine, July 1891.

Conan Doyle A. The Boscombe Valley mistery. London: Strand Magazine, October 1891

3 Conan Doyle A. A case of identity. London: Strand Magazine, September 1891.

14 Conan Doyle A. A study in scarlet. London: Beeton's Christmas Annual, 1887.

15 Conan Doyle A. The hound of the Baskervilles. London: Strand Magazine, August 1901 through April 1902.

16 Stout R. The Nero Wolfe omnibus. World, 1944.

17 Simenon G. Monsieur Gallet, décédé. Paris: Favard, 1933.

18 Christie A. Murder on the Orient Express. London: William Collins Sons \& Co, 1934

Co, 1934. Woodfield WR. Columbo and the murder of a
1991. Universal Reference Number 82204 .

20 Chandler R. The simple art of murder. New York: Ballantine, 1972.

(Accepted 27 September 2005) 